\title{
Straining mechanisms in aluminium alloy 6056. In-situ investigation by transmission electron microscopy
}

\author{
François Delmas ${ }^{\mathrm{a}, *}$, Marie Vivas ${ }^{\mathrm{b}}$, Philippe Lours $^{\mathrm{b}}$, Marie-José Casanove ${ }^{\mathrm{a}}$, \\ Alain Couret $^{\mathrm{a}}$, Armand Coujou ${ }^{\mathrm{a}}$ \\ ${ }^{\text {a } C E M E S / C N R S,} 29$ rue Jeanne Marvig, B.P 4347, 31055 Toulouse Cedex, France \\ ${ }^{\mathrm{b}}$ CROMEP, Ecole des Mines d'Albi-Carmaux, Campus Jarlard, 81013 Albi Cedex 09, France
}

\begin{abstract}
TEM in-situ straining tests, performed in precipitation hardened aluminium alloy 6056-T6, show that precipitates are sheared or by-passed by dislocations. By-passing, assisted by dislocation cross-slip, results in the formation and stress-induced spreading of non-planar loops. The relationship between those elementary mechanisms and the mechanical properties of the alloy is discussed.
\end{abstract}

Keywords: Aluminium alloys; Deformation micro-mechanisms; In-situ straining experiments; Precipitation hardening

\section{Introduction}

In precipitation hardened alloys, the interaction between dislocations and second phase precipitates, showing the occurrence of precipitate shearing and various modes of precipitate by-passing, have been investigated by transmission electron microscopy (TEM) [1,2]. TEM in-situ straining experiments allowing the investigation of the dynamics of those deformation mechanisms under controlled stress and temperature, permit identification of the various stages of the operative processes of plastic deformation as well as extraction of quantitative data [3-5]. This might help to improve manufacturing routes to optimise the mechanical performances of the material.

Because of its good mechanical properties, improved corrosion resistance and weldability, alloy 6056-T6 $(\mathrm{AlMgSi})$ will substitute for standard 2024 alloy $(\mathrm{AlCu})$ for the manufacturing of the forthcoming Airbus A380 fuselage skins. Tempering T6, corresponding to the hardening peak, promotes the precipitation of nanometer size second phase particles. From TEM in-

\footnotetext{
* Corresponding author. Tel.: +33-56-225-7870; fax: +33-56-2257999

E-mail address: delmas@cemes.fr (F. Delmas).
}

situ straining data in alloy 6056-T6, Vivas et al. [5] have measured the maximum force precipitates sustained prior to being sheared by dislocations.

In this paper, the different micro-mechanisms that control the plastic deformation and their relative efficiency as a function of both the test temperature and the applied stress are addressed. In the discussion, an attempt is made to correlate those microscopic mechanisms to the macroscopic tensile properties.

\section{Experimental}

Alloy 6056-T6 (Table 1) is cast and processed in the shape of polycrystalline sheets $1.5 \mathrm{~mm}$ thick. T6 treatment consists in solutionizing at $550{ }^{\circ} \mathrm{C}$, water quenching followed by tensile plastic straining $(2 \%)$ and tempering at $175^{\circ} \mathrm{C}$ during $8 \mathrm{~h}$.

The investigation of the material, conducted by TEM in-situ straining [6] and post-mortem analysis, suffers specific experimental constraints: (i) the selection of glide systems is not possible as material is polycrystalline, and (ii) the strain field of the precipitates, generally superimposed to that of the dislocations, hinders the simultaneous imaging of both defects. 
Table 1

Chemical composition of aluminium alloy 6056 (in wt.\%)

\begin{tabular}{llllllllll}
\hline $\mathrm{Si}$ & $\mathrm{Mg}$ & $\mathrm{Cu}$ & $\mathrm{Mn}$ & $\mathrm{Fe}$ & $\mathrm{Zn}$ & $\mathrm{Zr}$ & $\mathrm{Cr}$ \\
\hline 0.943 & 0.869 & 0.798 & 0.634 & 0.198 & 0.153 & 0.110 & 0.066 \\
\hline
\end{tabular}

\section{Results}

\subsection{General aspects}

Hardening precipitates in alloy 6056-T6 are finely distributed in the shape of needles and laths [7,8] with long axis parallel to the $\langle 100\rangle$ directions of the matrix and cross-sections of 7 and $6.5 \mathrm{~nm}^{2}$, respectively [7]. The volume density of the particles is estimated to be about $10^{17} \mathrm{~cm}^{-3}$ using either TEM [9] or small angle neutron scattering (SANS) [8].

Fig. 1 is a post mortem dark field image $(g=\overline{2} 20)$ of a foil taken from a tensile specimen plastically strained at room temperature $\left(\varepsilon_{\text {plastic }}=2 \%\right)$. The deformation is quite homogeneous and the dislocations do not show any specific characteristics. Note however the presence of a dispersoid, labelled $\mathrm{D}$ on which dislocations tend to accumulate, along with large loops for instance $b_{1}, b_{2}$ and $b_{3}$. Losses of contrast due to the compensatory effect of particle and dislocation strain fields occur along

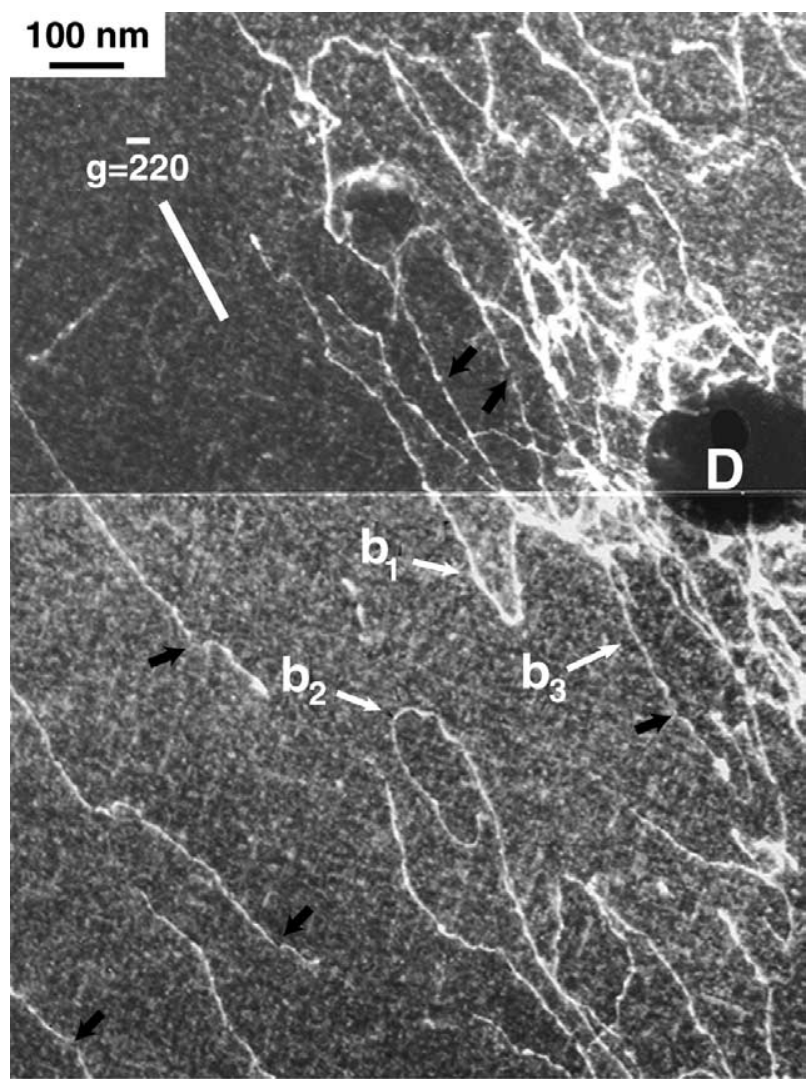

Fig. 1. Dark field image of a specimen strained at room temperature. many dislocation lines (marked with black arrows). From a detailed analysis of the in-situ observations, the mechanisms of loop formation are discussed in the next sections.

\subsection{Shearing mechanism}

A room temperature in situ straining sequence viewed in bright field condition is shown in Fig. 2 along with a sketch giving the detail of the shearing mechanism. In Fig. 2(a) corresponding to the initial state of deformation, the dislocation is bowed between precipitates, marked with arrows, under the effect of the applied stress. Precipitates are located using both the loss of contrast on the dislocation lines and the curvature of dislocation segments. This type of sequence is used to estimate the mean distance between precipitates that pin the dislocations, which is $30 \mathrm{~nm}$.

From Fig. 2(a) to (b), the dislocation escapes from obstacles at C, D and E on which it was initially pinned and propagates in its slip plane prior to lock again on precipitates at F, G, K, H, I and J. As those displacements occur with no loop formation, it is assumed that precipitates are sheared by dislocations. For a better evaluation of the dislocation displacement, the initial position of the defect is reported in Fig. 2(b).

\subsection{By-passing mechanism: formation of loops}

Overcoming of precipitates is illustrated in Fig. 3 corresponding to three successive steps of deformation for a specimen strained in the TEM at room temperature. Micrographs are bright field images taken with $g=11 \overline{1}$. From Fig. 3a to $\mathrm{b}$, a dislocation enters the investigated area and locks on precipitates $\mathrm{A}-\mathrm{H}$. Under the effect of the applied stress, the dislocation shears the particles A, C, D, F, G and $\mathrm{H}$ and by-passes the precipitates $\mathrm{B}$ and $\mathrm{E}$, leaving the loops I and $\mathrm{L}$.

Those loops are either: (i) small Orowan loops with diameter of the order of magnitude of the precipitate cross-section, or (ii) much larger loops, able to spread under the effect of the applied stress, formed by crossslip of the screw segments of the dislocation according to the mechanism reported in [10] and observed in other materials [11].

The undulated shape of the slip lines shown in Fig. 3(d) (in between $a$ and $b$ or $c$ and $d$ for instance) confirms the occurrence of easy dislocation cross-slip in this alloy. 

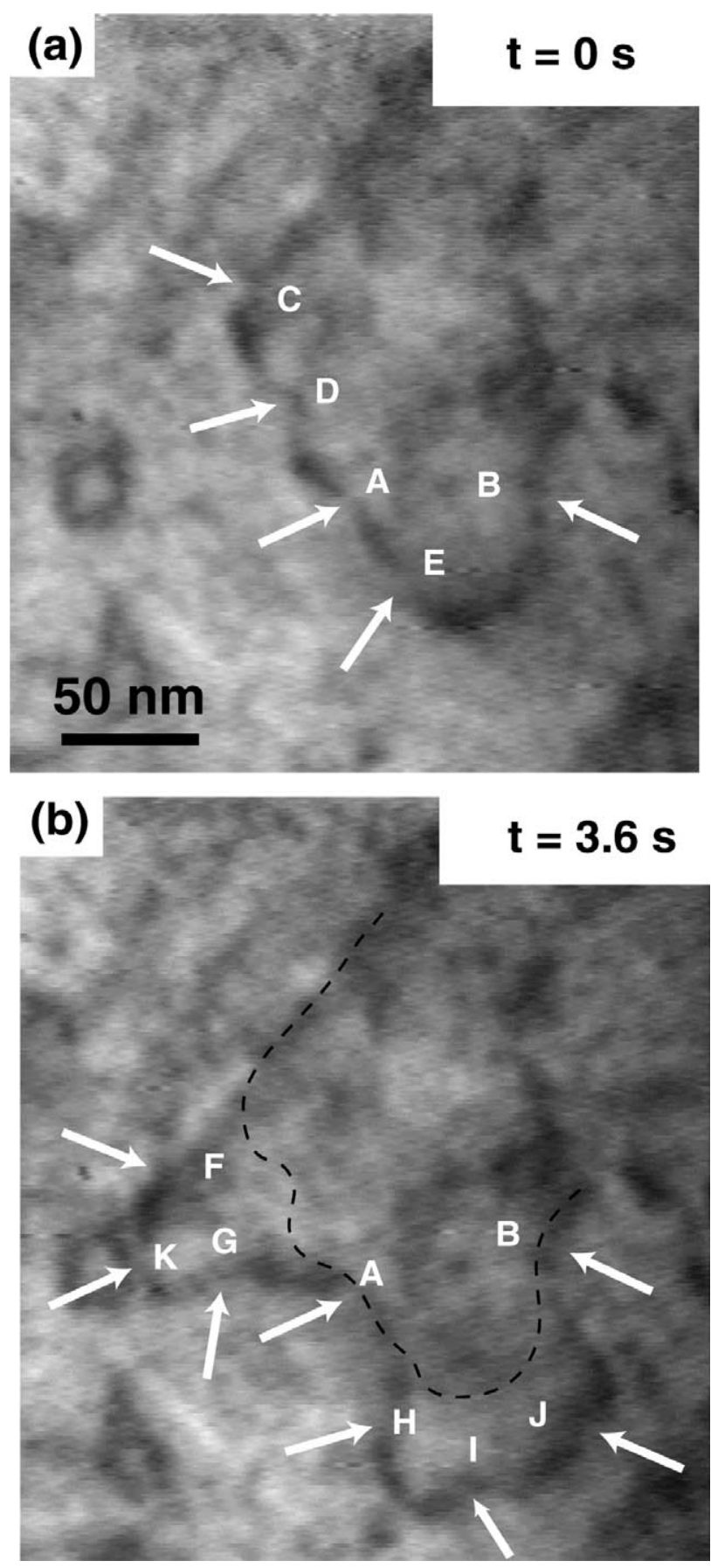

Fig. 2. TEM in-situ straining sequence at room temperature showing the shearing of precipitates by a dislocation.

\subsection{Spreading of loops: multiplication of dislocations}

Fig. 4 is a bright field sequence $(g=11 \overline{1})$ showing the stress induced spreading of a large loop at room temperature. At the initial stage of deformation (Fig. 4a), two dislocation loops $b_{1}$ and $b_{2}$, with Burgers vector $b=a / 2[0 \overline{1} 1]$ are present. The loop $b_{2}$ is pinned on precipitates A, B, C and D. From Fig. 4(a) to (b), the loop has spread under the effect of the load prior to pin on another series of precipitates (E, F, G and H). The subsequent step of deformation (Fig. 4(c)) shows the propagation in the (111) plane of the part of the loop initially pinned on precipitates I, J, K and L. The loop comes to pin on precipitates $\mathrm{M}, \mathrm{N}, \mathrm{O}$ and $\mathrm{P}$ with the screw segment KJ leaving the residual loop $b_{3}$. An additional loop $b_{4}$ is formed as the deformation proceeds between Fig. 4(c) and (e).

This type of sequence is typical of room temperature straining: once formed, the non-planar loops, spreading under stress, contribute to the dislocation multiplication by leaving residual non-planar loops able to subsequently spread aided by the applied stress.

In Fig. 4(f), the change in shape of the dislocation loop $b_{1}$, projected in the slip plane (111), is plotted as a function of the straining time. Spreading is roughly isotropic and depends very little on the dislocation character.

\subsection{Influence of temperature}

In-situ straining experiments as well as post mortem observations were performed at $-123,130$ and $150{ }^{\circ} \mathrm{C}$. Fig. 5 presents bright field images extracted from in-situ straining sequences at $-123{ }^{\circ} \mathrm{C}$ (a) and $130^{\circ} \mathrm{C}$ (b). In both cases, dislocations have left many loops with various sizes marked with arrows as they slipped and interacted with precipitates in the octahedral planes.

At low temperature, the mean size of the loops $\left(b_{1}, b_{2}\right.$, $b_{3}$ and $b_{4}$ for instance) is globally lower than at room temperature (Fig. 4) and most of all than at high temperature $\left(b_{5}, b_{6}, b_{7}\right.$ and $\left.b_{8}\right)$.

Whatever the testing temperature is, the deformation of the material is controlled by the interaction of dislocation loops with precipitates. However, the mechanism of loop spreading depends on temperature. At low temperature, some loops remain planar as the tendency for cross-slip is lower giving rise to the formation of Orowan loops with small sizes. At high temperatures, the particles may be circumvented by thermally activated cross-slip so that non-planar loops form with segments on the octahedral or even cube planes [12].

\section{Discussion}

TEM experimental data relative to the controlling mechanisms of deformation are discussed with respect to the macroscopic mechanical properties of the alloy. An attempt is made to correlate the microscopic observations of in-situ strained specimens to the tensile behaviour of the material.

TEM in-situ straining experiments show the occurrence of the following deformation micro-mechanisms: 

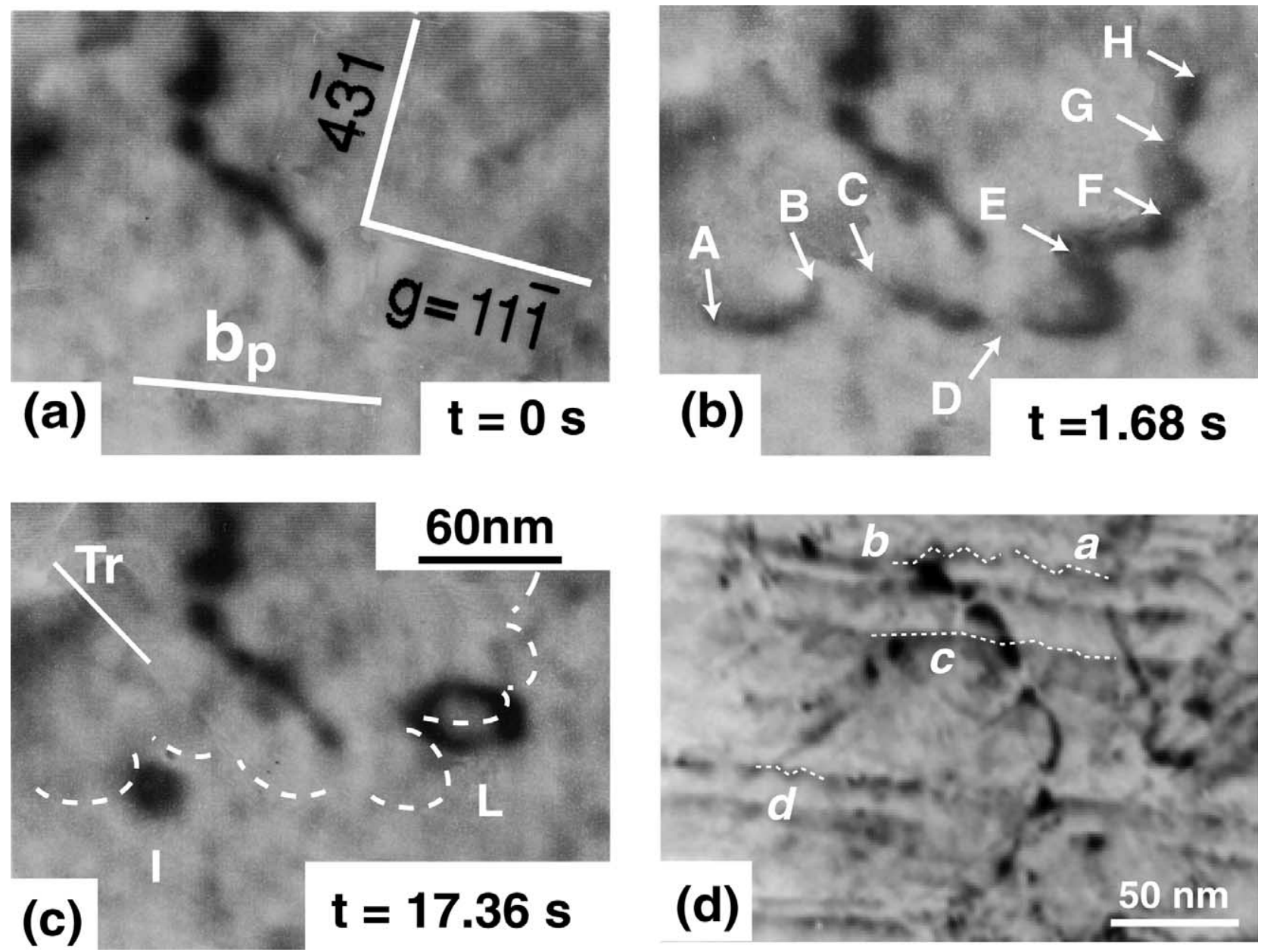

Fig. 3. In-situ observation of $(\mathrm{a}-\mathrm{c})$ the successive steps of a loop formation at room temperature, and (d) non-linear slip traces due to cross-slip.

- Shearing of precipitates by mobile dislocations is the prevalent elementary mechanism at room temperature.

- Precipitate overcoming, concomitant with the formation of non-planar loops, is due to dislocation crossslip. Spreading of these loops contributes to the multiplication of dislocations in the material. The probability of cross-slip and consequently the size of the non-planar loops increase with the test temperature.

- The isotropic spreading of the loops is the consequence of the independence of the force $F=d \tau b$, exerted by a dislocation on an array of precipitates, on the dislocation character ( $b$ is Burger vector, $d$ is the mean distance between precipitates).

- At low temperature, precipitates overcoming occur by by-passing processes leading to the formation of dipoles or Orowan loops. Cross-slip appears too difficult to promote the loop spreading observed at higher temperature.

Note that all these elementary mechanisms occur under the effect of the applied stress only, as no dislocation pile-ups and their concomitant effect of stress concentration were observed in the material.

Table 2 gives results of tensile tests (yield stress $\sigma_{\mathrm{E}}$ at $0,2 \%$ plastic strain and $\Delta \sigma / \Delta \varepsilon$ calculated at $\varepsilon=1 \%$ ) conducted at various temperature from -196 to $170{ }^{\circ} \mathrm{C}$ with a strain rate of $0.6 \times 10^{-4} \mathrm{~s}^{-1}$. Stress-strain curves, showing a slight increase of stress versus strain, for all temperatures indicate that little work hardening occurs. The yield stress decreases quasi-linearly from 196 to $125^{\circ} \mathrm{C}$ by approximately $0.2 \mathrm{MPa} \mathrm{K}{ }^{-1}$, then drops more drastically above this temperature (0.6 MPa $\mathrm{K}^{-1}$ ) and $\Delta \sigma / \Delta \varepsilon$ decreases from 2000 to $960 \mathrm{MPa}$. It was shown elsewhere [9] that the high yield stress of the material is due to the specific strength and distribution of hardening precipitates. Those parameters are constant with temperature and the variations of $\sigma_{\mathrm{E}}(\mathrm{T})$ and $\Delta \sigma / \Delta \varepsilon$ (T) are likely due to the enhancement of the probability of precipitate by-passing associated to the thermally activated cross-slip of the dislocations, in particular for high temperatures.

The easy cross-slip for dislocations, related to the high stacking fault energy $\left(150 \mathrm{~mJ} \mathrm{~m} \mathrm{~m}^{-2}\right)$, is the major 

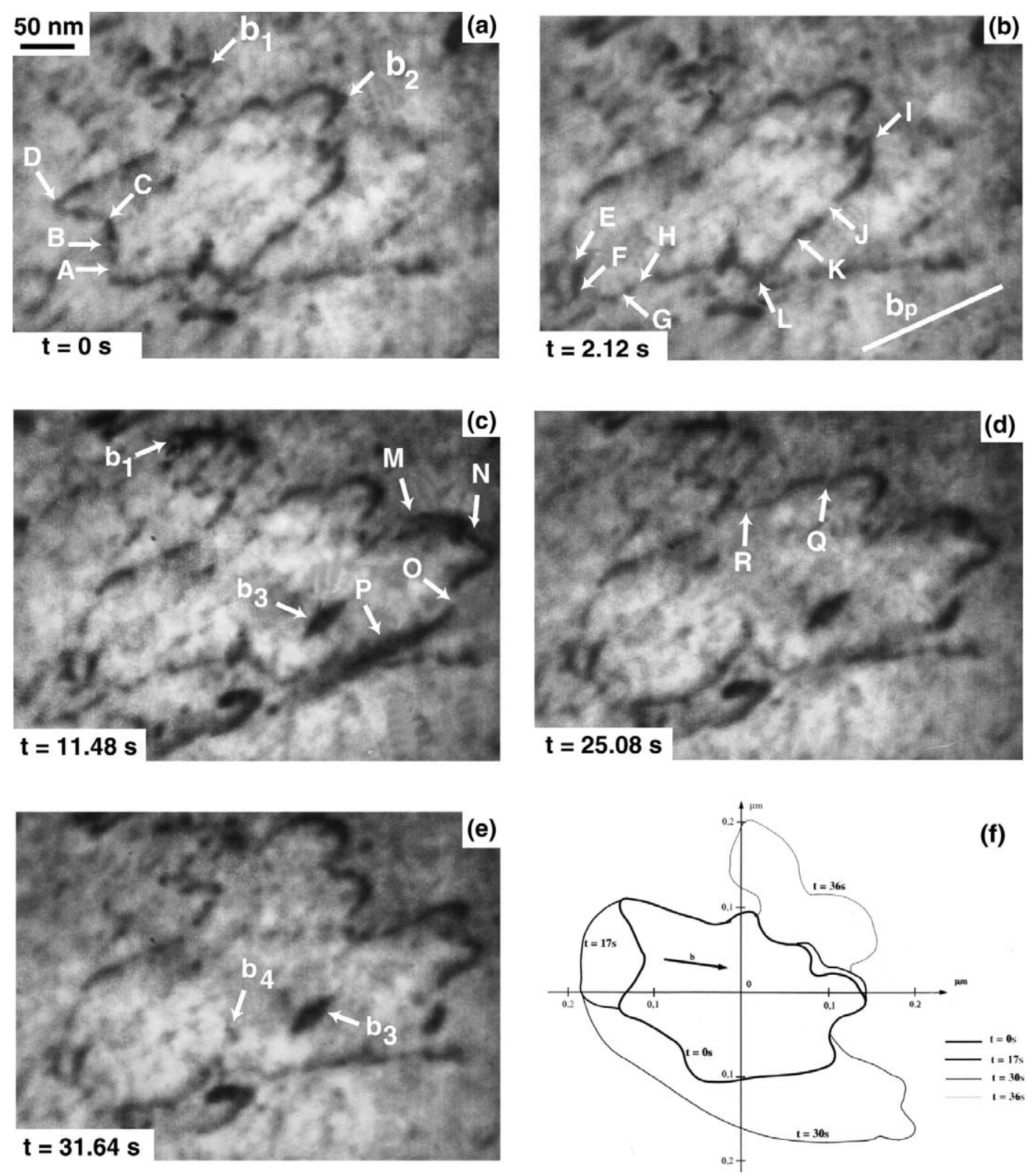

Fig. 4. (a-e) TEM in situ straining sequence at room temperature showing the spreading of a loop, and (f) schematic spreading of the dislocation loop as a function of straining time.

mechanism that controls the mechanical strength of the alloy:

- Because dislocation pile-up cannot form in the material, breaking of obstacles is not aided by internal stress concentration and required a high applied stress.

- Because it is thermally activated, by-passing of precipitates increases with temperature, and consequently explains the decrease of the yield stress above $125^{\circ} \mathrm{C}$. However, the high aspect ratio of the needlelike precipitates, limiting the effect of cross-slip, partially compensates the thermal activation and the flow stress remains high at elevated temperature.

\section{Conclusion}

Conventional TEM and in situ straining investigation of alloy 6056-T6 show that the shearing of strengthening precipitates by dislocations is the prevalent mechanism that controls the plastic deformation of the material. Bypassing of particles, assisted by cross-slip, is an additional process whose effects are enhanced when the temperature increases consistently with the correlated 

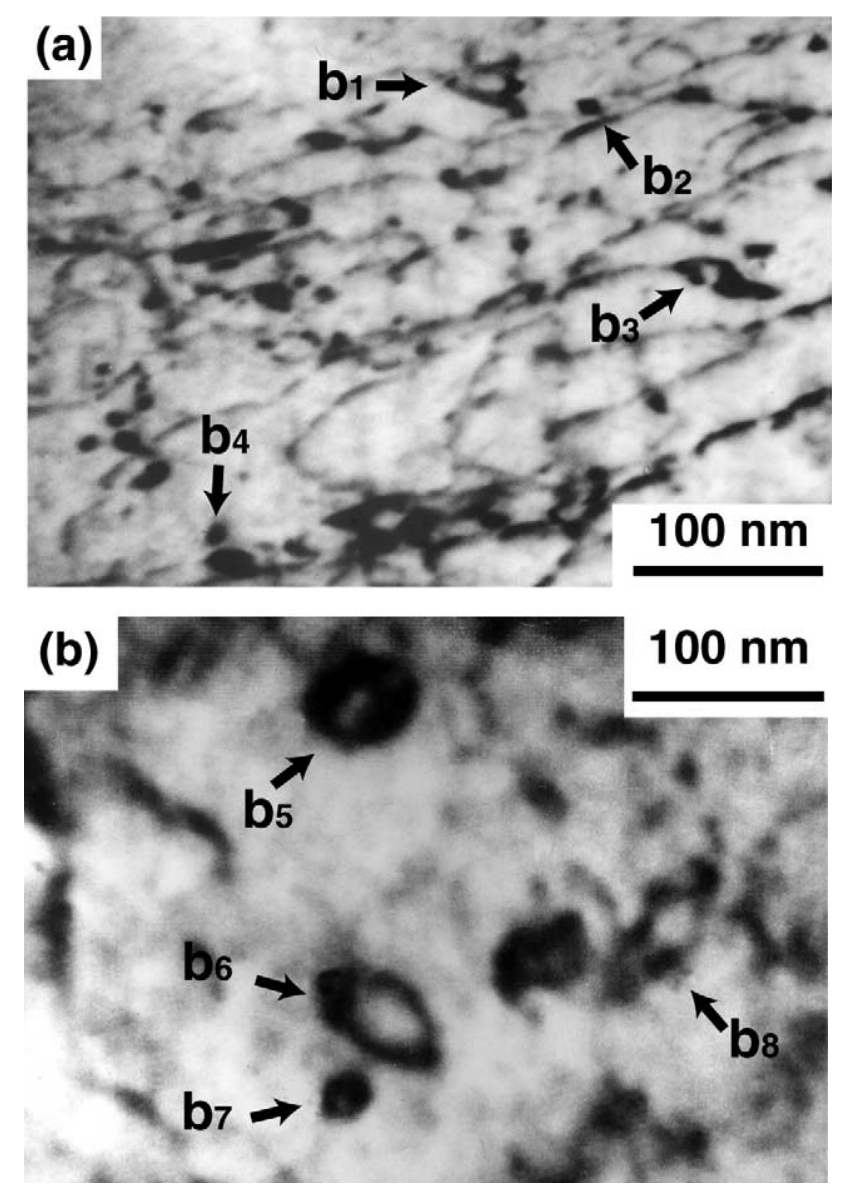

Fig. 5. TEM bright field images extracted from in situ straining sequences at (a) $-123{ }^{\circ} \mathrm{C}$ and (b) $+130{ }^{\circ} \mathrm{C}$.

decrease of the flow stress and the hardening rate. This non-planar mechanism leads to a work hardening of the alloy which limits the effect of internal stress and results in a high mechanical strength.
Table 2

Variation of yield stress and $\Delta \sigma / \Delta \varepsilon$ versus temperature for the 6056-T6 alloy

\begin{tabular}{lrrrl}
\hline & $-196^{\circ} \mathrm{C}$ & $20^{\circ} \mathrm{C}$ & $125^{\circ} \mathrm{C}$ & $170^{\circ} \mathrm{C}$ \\
\hline$\sigma_{\mathrm{E}}(\mathrm{MPa})$ & 400 & 355 & 315 & 285 \\
$\Delta \sigma / \Delta \varepsilon(\mathrm{MPa})$ & 2000 & 1650 & 1250 & 960 \\
\hline
\end{tabular}

\section{Acknowledgements}

This work is supported by LRAMSA (Laboratoire Régional pour l'Amélioration des Matériaux Structuraux pour l'Aéronautique) of Midi-Pyrénées county. The authors acknowledge Péchiney-CRV for providing the 6056 alloy.

\section{References}

[1] P.B. Hirsch, F.J. Humphreys, in: A. Argon (Ed.), Physics of Strength and Plasticity, MIT Press, Cambridge, MA, 1969.

[2] V. Gerold, in: F.R.N. Nabarro (Ed.), Dislocations in Solids (Section 15), 1979, p. 221.

[3] M. Nemoto, S. Koda, Trans. JIM 7 (1966) 235.

[4] U. Messerschmidt, F. Appel, M. Bartsch, R. Gerlach, Phys. Stat. Sol. (a) 78 (1983) 93.

[5] M. Vivas, P. Lours, C. Levaillant, A. Couret, M.J. Casanove, A. Coujou, Phil. Mag. A 76 (1997) 921.

[6] A. Couret, J. Crestou, S. Farenc, G. Molénat, N. Clément, A. Coujou, D. Caillard, Microscopy Microanal. Microstructures 4 (1993) 153.

[7] M. Vivas, P. Lours, C. Levaillant, A. Couret, M.J. Casanove, A. Coujou, Mater. Sci. Eng. A234-236 (1997) 664.

[8] P. Donnadieu, F. Carsughi, A. Redjaïmia, C. Diot, G. Lapasset, J. Appl. Cryst. 31 (1998) 212

[9] M. Vivas, Thesis, Toulouse, France, 1997.

[10] E. Furubayashi, J. Phys. Soc. Jpn. 27 (1969) 130.

[11] A. Couret, D. Caillard, Acta Metall. 33 (1985) 1447.

[12] F. Delmas, J. Majimel, G. Molénat, A. Couret, A. Coujou, in press. 